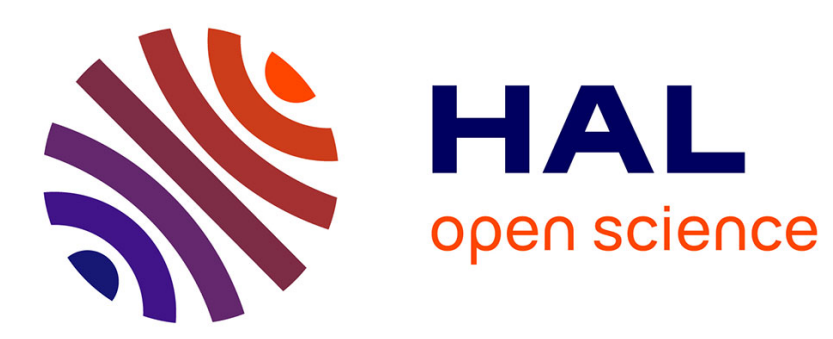

\title{
A Plea for AUC Confidence Intervals in Diagnosis Models used in Gynecology
}

Brahim Hamadicharef

\section{To cite this version:}

Brahim Hamadicharef. A Plea for AUC Confidence Intervals in Diagnosis Models used in Gynecology. BioMedical Engineering and Informatics (BMEI2010), Oct 2010, Yantai, China. pp.2471-2474. hal00530518

\section{HAL Id: hal-00530518 https://hal.science/hal-00530518}

Submitted on 29 Oct 2010

HAL is a multi-disciplinary open access archive for the deposit and dissemination of scientific research documents, whether they are published or not. The documents may come from teaching and research institutions in France or abroad, or from public or private research centers.
L'archive ouverte pluridisciplinaire HAL, est destinée au dépôt et à la diffusion de documents scientifiques de niveau recherche, publiés ou non, émanant des établissements d'enseignement et de recherche français ou étrangers, des laboratoires publics ou privés. 


\title{
A Plea for AUC Confidence Intervals in Diagnosis Models used in Gynecology
}

\author{
Brahim Hamadicharef \\ Tiara \#22-02, 1 Kim Seng Walk, Singapore 239403 \\ Email: bhamadicharef@hotmail.com
}

\begin{abstract}
Over the last decade many studies in the gynecology literature have been investigating the performance of diagnosis models such as Univariate, Risk of Malignancy Index (RMI) and Logistic Regression (LR). Typical performance results are claimed in terms of sensitivity (SEN), specificity (SPE), accuracy (ACC), Positive Predictive Value (PPV), Negative Predictive Value (NPV), with some studies als including Receiver Operating Characteristic (ROC) curve and its Area Under the Curve (AUC). It remains, however, that all these measures do not reflect any sample size and thus making it sometimes difficult to assess with confidence the true performance of these diagnosis models, in particular for small sample size. In this paper, we propose to use systematically, a ROC-based methodology that makes possible to calculate the Confidence Interval (CI) at each ROC point. The methodology is generic and robust to sample size, and based on Probability Density Function (PDF) without any assumption on the distribution. We illustrate its use on 6 recent studies and show that results with the additional AUC 95\% CI contour is more adequate to compare the performance of these diagnosis models, especially with studies using different sample size.
\end{abstract}

\section{INTRODUCTION}

Numerous studies, in the gynecology literature, provide performance of diagnosis models such as univariate models, Risk of Malignancy Index (RMI) [1][2] and Logistic Regression (LR) [3][4]. Performance results are typically presented as sensitivity (SEN), specificity (SPE), accuracy (ACC), Positive Predictive Value (PPV), Negative Predictive Value (NPV). Some studies include additional Receiver Operating Characteristic (ROC) analysis with a ROC curve, calculation of the Area Under the Curve (AUC) [5] and Standard Error (SE) [6]. It remains, however, that all these measure do not reflect any sample size and thus making it difficult to assess with confidence the true performance of the models and diagnosis. A methodology that would take into account sample size would also be very useful when comparing results from studies with different sample size.

In this paper we introduce a methodology originally developed by Tilbury [7] that allow to calculate, at a defined level of confidence (typically 0.05 for $95 \%$ ), the Confidence Interval (CI) contour for each point of the ROC curve. We illustrate its use with recent studies taken from the gynecology literature presented by Yamamoto [8], Manjunath [9], Ma [10], Obeidat [2], Ulusoy [11], and Aslam [12].

The rest of the paper is organized as follow. In Section II we formulate the problem. The most commonly used diagnosis models in gynecology are presented in Section III. In Section IV we illustrate the novel approach with results from
TABLE I

SINGLE THRESHOLD CONTINGENCY

\begin{tabular}{|c|c|c|}
\hline & \multicolumn{2}{|c|}{ Gold Standard } \\
\hline & Malign & Benign \\
\hline $\begin{array}{l}\text { Malign } \\
\text { (Positive) }\end{array}$ & $\begin{array}{c}\text { True Positive } \\
\text { (TP) }\end{array}$ & $\begin{array}{c}\text { False Positive } \\
\text { (FP) }\end{array}$ \\
\hline $\begin{array}{l}\text { Benign } \\
\text { (Negative) }\end{array}$ & $\begin{array}{c}\text { False Negative } \\
\text { (FN) }\end{array}$ & $\begin{array}{c}\text { True Negative } \\
\text { (TN) }\end{array}$ \\
\hline & nMal & nBen \\
\hline
\end{tabular}

recent studies in gynecology. Finally, we conclude the paper in Section V.

\section{Problem Formulation}

Let us consider the following typical scenario. The outcome of a classifier for a 2-class medical diagnosis (benign or malignant, i.e. from the Ground Truth) can be of four types: True Positive (TP) when the tumor is malignant and diagnosed correctly, True Negative (TN) when the tumor is benign and diagnosed correctly, False Positive (FP) when the tumor is benign but diagnosed incorrectly as malignant, and False Negative (FN) when the tumor is malignant but diagnosed incorrectly as benign. These are shown in Table I. We know that the sample size of each groups is $n B e n=T N+F P$ and $\mathrm{nMal}=\mathrm{TP}+\mathrm{FN}$. Using these counts, one can calculate he sensitivity and specificity performance measures, typically published in the literature together with sample size of the benign (nBen) and malignant (nMal) groups. As a reminder, sensitivity and specificity are defined as $\frac{T P}{T P+F N}$ and $\frac{T N}{T N+F P}$, respectively. As useful and informative these performance measure can be to the clinical gynecologist, they lack any sense/dimension of sample size. A sensitivity of $80 \%$ could be from different ratios with different sample sizes. Measures such as Positive Predictive Value (PPV) and Negative Predictive Value (NPV) are use in gynecology research and also suffer from the same sample issue issue. There is thus a need to provide confidence Interval (CI) (e.g. 95\%CI), for each point of the ROC curve, that will allow for e.g. to compare results from studies with different sample size.

Tilbury [7] proposed a ROC-based methodology for performance evaluation of intelligent medical systems as a Bayesian approach to the AUC CI calculation, which was shown particularly suitable for small sample size (more details in [13]). WE 
TABLE II

SUMMARY OF RECENT STUDIES

\begin{tabular}{|c|c|c|c|c|c|c|}
\hline Study & $\begin{array}{l}\text { Sen / Spe } \\
(\% / \%)\end{array}$ & $\begin{array}{c}\text { AUC } \\
\text { AUC-L }(95 \% \mathrm{CI}) \\
\end{array}$ & $\mathrm{TP}$ & $\mathrm{TN}$ & FP & FN \\
\hline \multicolumn{7}{|c|}{ Yamamoto $[8](\mathrm{nBen}=213 / \mathrm{nMal}=40)$} \\
\hline RMI1 (150) & $85.0 / 83.1$ & $0.840(0.752)$ & 34 & 177 & 36 & 6 \\
\hline RMI2 (200) & $90.0 / 82.6$ & $0.863(0.781)$ & 36 & 176 & 37 & 4 \\
\hline RMI3 (150) & $85.0 / 83.1$ & $0.840(0.752)$ & 34 & 177 & 36 & 6 \\
\hline RMI4 (450) & $87.5 / 91.1$ & $0.893(0.809)$ & 35 & 194 & 19 & 5 \\
\hline \multicolumn{7}{|c|}{ Manjunath $[9](\mathrm{nBen}=55 / \mathrm{nMal}=93)$} \\
\hline RMI3 (200) & $74.2 / 90.9$ & $0.826(0.743)$ & 69 & 50 & 5 & 24 \\
\hline CA125 (150 & $73.1 / 92.7$ & $0.829(0.749)$ & 68 & 51 & 4 & 25 \\
\hline UltraSound1 & $50.5 / 56.4$ & $0.535(0.432)$ & 47 & 31 & 24 & 46 \\
\hline UltraSound2 & $43.0 / 89.1$ & $0.661(0.574)$ & 40 & 49 & 6 & 53 \\
\hline Post-Menopause & $48.4 / 65.5$ & $0.569(0.467)$ & 45 & 36 & 19 & 48 \\
\hline \multicolumn{7}{|c|}{ Ma $[10](\mathrm{nBen}=77 / \mathrm{nMal}=63)$} \\
\hline RMI (400) & $79.4 / 94.8$ & $0.871(0.792)$ & 50 & 73 & 4 & 13 \\
\hline CA125 (200) & $65.1 / 94.8$ & $0.799(0.715)$ & 41 & 73 & 4 & 22 \\
\hline UltraSound & $93.7 / 83.1$ & $0.884(0.809)$ & 59 & 64 & 13 & 4 \\
\hline Post-Menopause & $55.6 / 79.2$ & $0.674(0.577)$ & 35 & 61 & 16 & 28 \\
\hline \multicolumn{7}{|c|}{ Obeidat $[2](\mathrm{nBen}=28 / \mathrm{nMal}=72)$} \\
\hline RMI (200) & $90.3 / 89.3$ & $0.898(0.793)$ & 65 & 25 & 3 & 7 \\
\hline CA125 (300) & $84.7 / 71.4$ & $0.781(0.656)$ & 61 & 20 & 8 & 11 \\
\hline UltraSound & $80.6 / 57.1$ & $0.688(0.561)$ & 58 & 16 & 12 & 14 \\
\hline Post-Menopause & $77.8 / 53.6$ & $0.657(0.529)$ & 56 & 15 & 13 & 16 \\
\hline \multicolumn{7}{|c|}{ Ulusoy [11](nBen = $190 / \mathrm{nMal}=106)$} \\
\hline Age (54) & $35.8 / 82.1$ & $0.590(0.525)$ & 38 & 156 & 34 & 68 \\
\hline RMI (153) & $76.4 / 77.9$ & $0.772(0.706)$ & 81 & 148 & 42 & 25 \\
\hline CA125 (80) & $65.1 / 82.1$ & $0.736(0.668)$ & 69 & 156 & 34 & 37 \\
\hline UltraSound1 & $100.0 / 77.4$ & $0.887(-)$ & 106 & 147 & 43 & 0 \\
\hline UltraSound2 & $8.5 / 66.8$ & $0.377(0.325)$ & 9 & 127 & 63 & 97 \\
\hline Post-Menopause & $46.2 / 67.9$ & $0.571(0.499)$ & 49 & 129 & 61 & 57 \\
\hline \multicolumn{7}{|c|}{ Aslam $[12](\mathrm{nBen}=67 / \mathrm{nMal}=33)$} \\
\hline LR1 [3] & $45.5 / 92.5$ & $0.690(0.581)$ & 15 & 62 & 5 & 18 \\
\hline LR2 [15] & $9.1 / 98.5$ & $0.538(0.484)$ & 3 & 66 & 1 & 30 \\
\hline LR3 [4] & $72.7 / 91.0$ & $0.819(0.706)$ & 24 & 61 & 6 & 9 \\
\hline LR4=LR1+LR2 & $60.6 / 92.5$ & $0.766(0.652)$ & 20 & 62 & 5 & 13 \\
\hline LR5=LR1+LR3 & $78.8 / 94.0$ & $0.864(0.757)$ & 26 & 63 & 4 & 7 \\
\hline LR6=LR2+LR3 & $72.7 / 83.6$ & $0.782(0.663)$ & 24 & 56 & 11 & 9 \\
\hline LR7=All & $78.8 / 94.0$ & $0.864(0.757)$ & 26 & 63 & 4 & 7 \\
\hline
\end{tabular}

use a fast computation formulation for calculating the lower and upper bounds of AUC CIs, recently proposed in [14].

\section{Diagnosis Models}

The most common diagnosis models in ovarian cancer research include univariate, Risk of Malignancy Index (RMI) and Logistic Regression (LR). Univariate models take a single variable such as post-menopause score, ultrasound score, serum CA125 level as unique feature and a diagnosis decision is taken by a threshold. Risk of Malignancy Index (RMI), first introduced by Jacobs [16], combines variables as follow:

$$
R M I=U \times M \times C A 125
$$

where $\mathrm{M}$ post-menopause score $(\mathrm{M}=1$ when patient is premenopause and $\mathrm{M}=3$ when patient is post-menopause), $\mathrm{U}$ is the ultrasound score (typically a total ultrasound score of 0 or 1 yielded $\mathrm{U}=1$, and a score of $\geq 2$ yielded $\mathrm{U}$ $=4$ [17]) and CA125 is a direct measure, typically in $\mathrm{ml}$, of the level of CA125 serum. The RMI model, simple in its calculation and interpretation, has been the subject of numerous studies [18][17][19][1].

In recent years, Logistic Regression (LR) models have gained popularity in gynecology [20][21]. It aims to predict an outcome from multiple variables, using a form as:

$$
y(X)=\frac{1}{1+e^{-\left(\beta_{0}+\sum_{i=1}^{N} \beta_{i} x_{i}\right)}}
$$

where $N$ the number of variables, $\mathrm{X}$ is set of variables, and $\beta_{0} \ldots \beta_{N}$ are the regression coefficients estimated using maximum-likelihood and the least-squares regression fitting procedures.

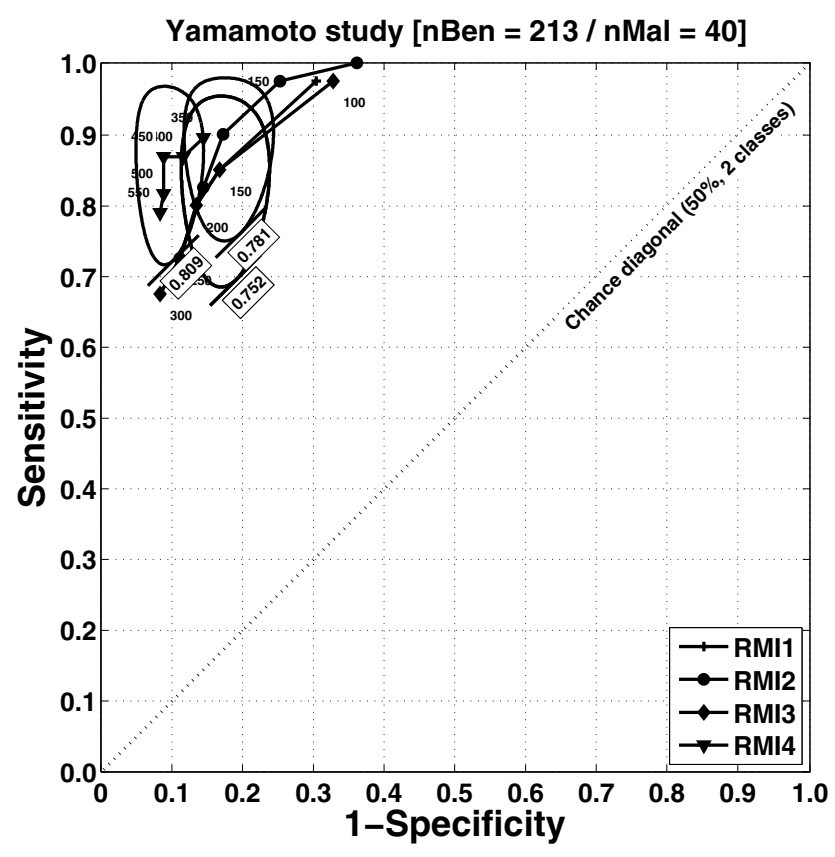

Fig. 1. Results of Yamamoto's study [8](N=253)

\section{Results FROM RECENT STUdies}

We re-examined the results from few recent studies using our approach. For each model of each study, the sensitivity and specificity are summarized in Table II. Using our approach we calculate AUC at the ROC point and AUC-L, the 95\% CI AUC lower bound. We also indicate the sample size in each group, with number of benign (nBen) and malignant (nMal) cases.

ROC curves for each models in each study are used to assess the $95 \%$ CI contour. ROC curve with $95 \%$ CI contours 


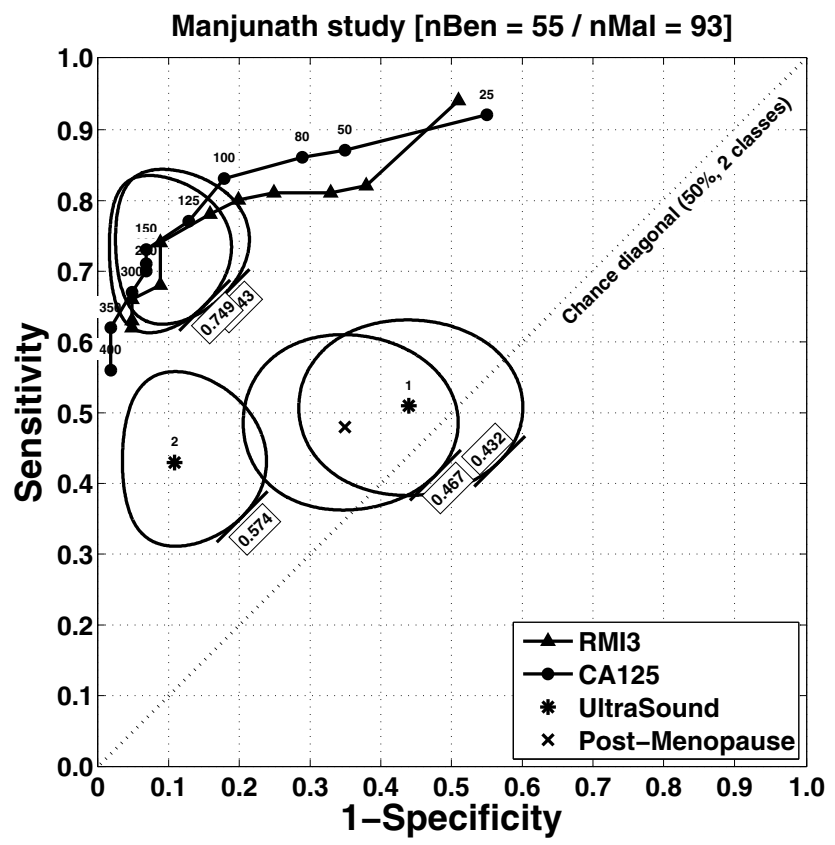

Fig. 2. Results of Manjunath's study [9] $(\mathrm{N}=148)$

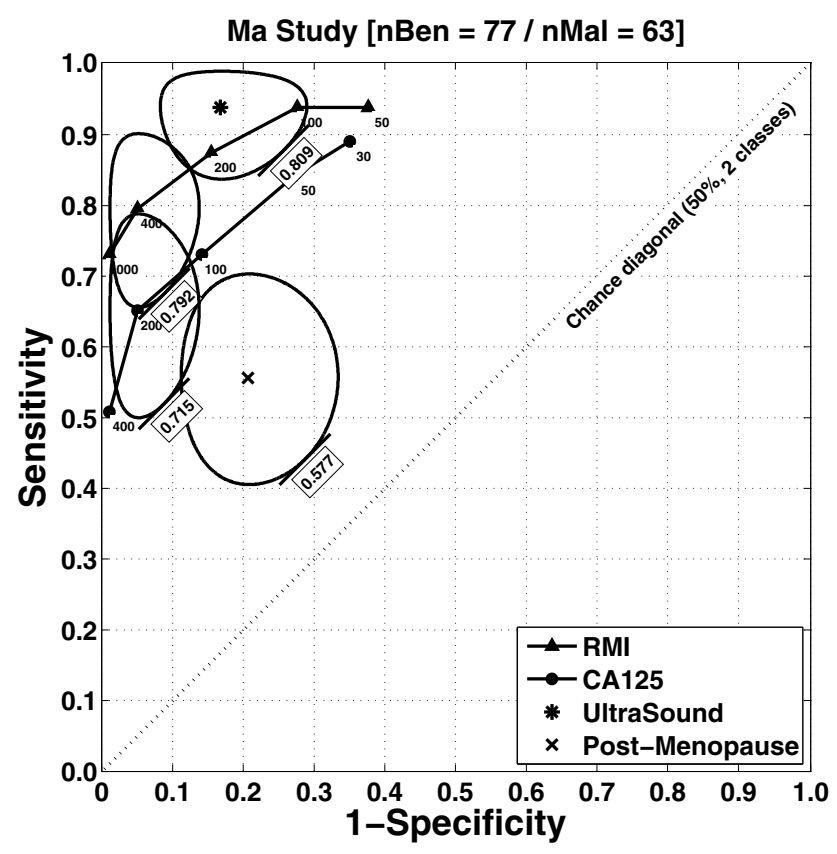

Fig. 3. Results of Ma's study [10] $(\mathrm{N}=140)$

are plotted for each model. Results from the Yamamoto's study [8] are presented in Figure 1, results from the Manjunath's study [9] are shown in Figure 2, from Ma's study [10] in Figure 3, those of Obeidat's study [2] in Figure 4, of Ulusoy's study [11] in Figure 5, and finally, results from the Aslam's study [12] are shown in Figure 6.

Due to the different performance and differences in sample size (both in terms of total number but also different ratio between benign and malignant), the $95 \% \mathrm{CI}$ contours are large

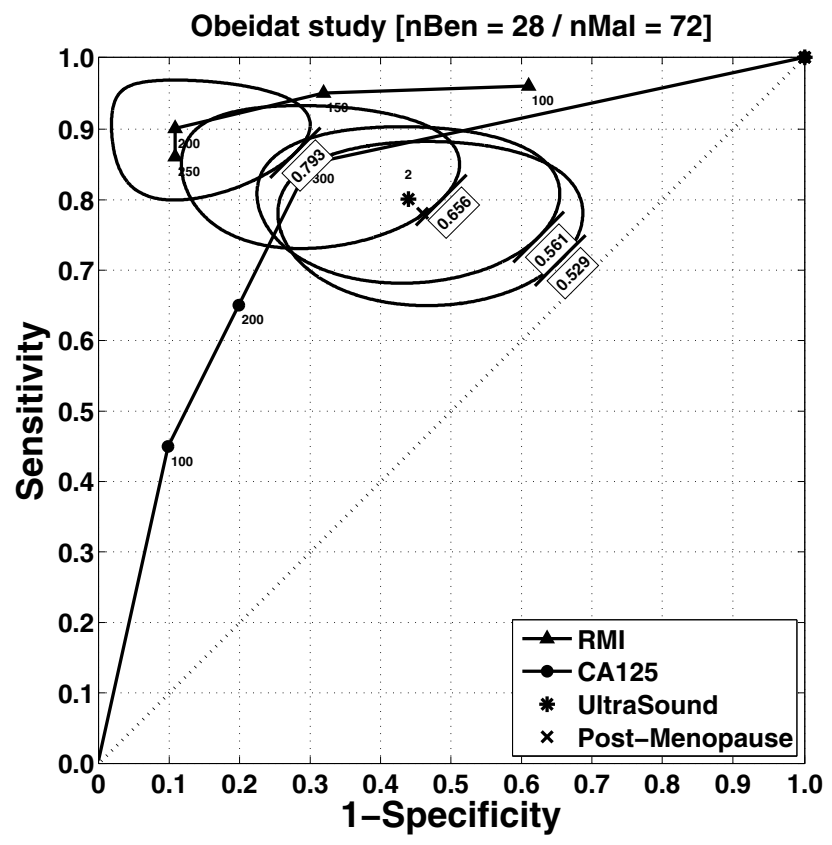

Fig. 4. Results of Obeidat's study [2] $(\mathrm{N}=100)$

and stretched. Some of the model have the contour close or even overlapping the level of chance (diagonal line) and thus their performance should be considered with more care.

\section{CONCLUSIONS}

In this paper, we presented a novel approach to visualize the performance of medical diagnosis models that overcome the issue of different sample size. It is recognized that as performance evaluation is typical claimed in terms of the sensitivity and specificity, and that, however, the sample size is rarely taken into consideration. Using the CI contour at the ROC, the methodology provide adequate visual indication as true performance (using the lower bound of the CI contour). We illustrated the methodology with the re-examination of the results from recently published studies which compared the performance of univariate, RMI and LR models for the diagnosis of ovarian cancer. Using the ROC with CI contour, one can assess the true performance of these diagnosis models, and furthermore, can assess any overlap of the CI contour with chance line and compare models all together considering that the difference in sample size is taken into account by the CI contour calculation.

Finally, it should be reminded that only the use of larger data set, such as the one created for the International Ovarian Tumor Analysis (IOTA) group with 1066 (800 benign and 266 malignant) patients [22], will give make the CI contour shrink and provide good confidence in the diagnosis performance.

\section{REFERENCES}

[1] S. Ma, K. Shen, and J. Lang, "A risk of malignancy index in preoperative diagnosis of ovarian cancer," Chinese Medical Journal, vol. 116, no. 3, pp. 396-399, 2003. 


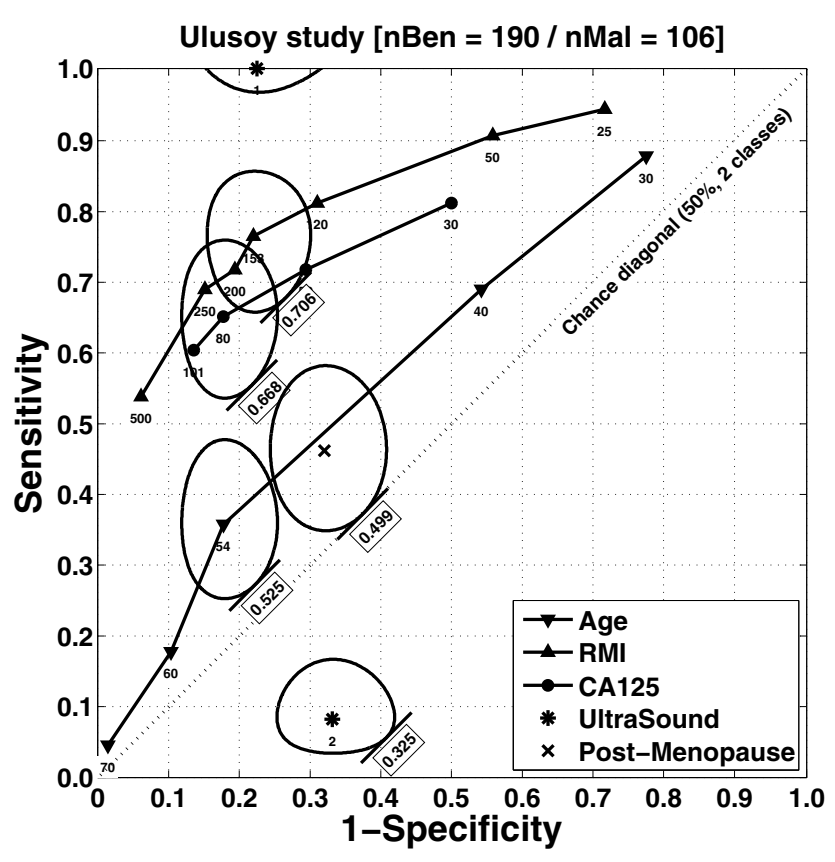

Fig. 5. Results of Ulusoy's study [11](N=296)

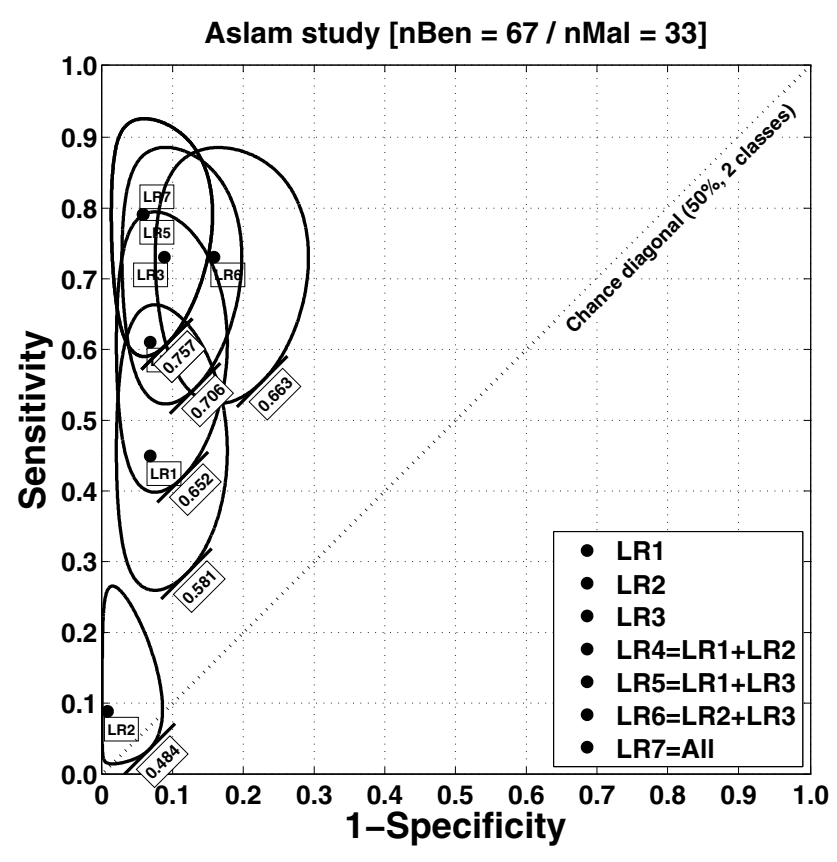

Fig. 6. Results of Aslam's study [12](N=140)

[2] B. R. Obeidat, Z. O. Amarin, J. A. Latimer, and R. A. Crawford, "Risk of malignancy index in the preoperative evaluation of pelvic masses," International Journal of Gynecology \& Obstetrics, vol. 85, no. 3, pp. 255-258, June 2004.

[3] A. Tailor, D. Jurkovic, T. H. Bourne, W. P. Collins, and S. Campbell, "Sonographic prediction of malignancy in adnexal masses using multivariate logistic regression analysis," Ultrasound in Obstetrics and Gynecology, vol. 10, no. 1, pp. 41-47, July 1997.

[4] D. Timmerman, H. Verrelst, T. H. Bourne, B. De Moor, W. P. Collins, I. Vergote, and J. Vandewalle, "Artificial neural network models for the preoperative discrimination between malignant and benign adnexal masses," Ultrasound in Obstetrics and Gynecology, vol. 13, no. 1, pp.
17-25, January 1999.

[5] J. A. Hanley and B. J. McNeil, "The Meaning and Use of the Area under a Receiver Operating Characteristic (ROC) Curve," Radiology, vol. 143, no. 1, pp. 29-36, April 1982

[6] _ - "A Method of Comparing the Areas under ROC curves derived from same cases," Radiology, vol. 148, pp. 839-843, 1983.

[7] J. Tilbury, P. Van-Eetvelt, J. Garibaldi, J. Curnow, and E. Ifeachor, "Receiver Operator Characteristic Analysis for Intelligent Medical Systems A New Approach for Finding Confidence Intervals," IEEE Transactions on Biomedical Engineering, vol. 47, no. 7, pp. 952-963, July 2000.

[8] Y. Yamamoto, R. Yamada, H. Oguri, N. Maeda, and T. Fukaya, "Comparison of four malignancy risk indices in the preoperative evaluation of patients with pelvic masses," European Journal of Obstetrics \& Gynecology and Reproductive Biology, vol. 144, pp. 163-167, 2009.

[9] A. P. Manjunath, Pratapkumar, K. Sujatha, and R. Vani, "Comparison of Three Risk of Malignancy Indices in Evaluation of Pelvic Masses," Gynecologic Oncology, vol. 81, no. 2, pp. 225-229, May 2001.

[10] S. Ma, K. Shen, and J. Lang, "A risk of malignancy index in preoperative diagnosis of ovarian cancer," Chin Med J, vol. 116, no. (Suppl 3), pp. 396-399, 2003.

[11] S. Ulusoy, O. Akbayir, C. Numanoglu, N. Ulusoy, E. Odabas, and A. Gulkilik, "The risk of malignancy index in discrimination of adnexal masses," International Journal of Gynecology and Obstetrics, vol. 96, no. 3, pp. 186-191, March 2007.

[12] N. Aslam, S. Banerjee, J. Carr, M. Savvas, R. Hooper, and D. Jurkovic, "Prospective Evaluation of Logistic Regression Models for the Diagnosis of Ovarian Cancer," Obstetrics \& Gynecology, vol. 96, no. 1, pp. 75-80, July 2000

[13] J. B. Tilbury, "Evaluation of Intelligent Medical Systems," Ph.D. thesis, Department of Communications and Electronic Engineering (DCEE), University of Plymouth, Drake Circus, Plymouth PL4 8AA, Devon, United Kingdom, September 2002.

[14] B. Hamadicharef, "Frequentist versus Bayesian approaches for AUC Confidence Interval Bounds," Proceedings of the 10th International Conference on Information Science, Signal Processing and their applications (ISSPA2010), Kuala Lumpur, Malaysia, May 10-13, 2010, pp. 341-344.

[15] J. L. Alcazar and M. Jurado, "Using a logistic model to predict malignancy of adnexal masses based on menopausal status, ultrasound morphology, and color Doppler findings," Gynecology Oncology, vol. 69, pp. 146-150, 1998.

[16] I. Jacobs and et al, "A risk of malignacy index incorporating Ca125, ultrasound and menopausal status for the accurate preoperative diagnosis of ovarian cancer," British Journal of Obstetrics and Gynaecology, vol. 97, pp. 922-929, 1990.

[17] S. Tingulstad, B. Hagen, F. E. Skjeldestad, M. Onsrud, T. Kiserud, T. Halvorsen, and K. Nustad, "Evaluation of a risk of malignancy index based on serum Ca125, ultrasound findings and menopausal status in the pre-operative diagnosis of pelvic masses," British Journal of Obstetrics and Gynaecology, vol. 103, no. 8, pp. 826-831, August 1996.

[18] J. Bailey, A. Tailor, R. Naik, A. Lopes, K. Godfrey, H. M. Hatem, and J. Monaghan, "Risk of malignancy index for referral of ovarian cancer cases to a tertiary center: does it identify the correct cases?" International Journal of Gynecological Cancer, vol. 16, pp. 30-34, February 2006.

[19] I. Jacobs, S. Skates, A. P. Davies, R. Woolas, A. Jeyerajah, P. Weidemann, K. Sibley, and D. Oram, "Risk of diagnosis of ovarian cancer after raised serum CA 125 concentration: a prospective cohort study," British Medical Journal, vol. 313, no. 7069, pp. 1355-1358, November 1996.

[20] K. S. Khan, P. F. W. Chien, and L. S. Dwarakanath, "Logistic Regression Models in Obstetrics and Gynecology Literature," Obstetrics and Gynecology, vol. 93, no. 6, pp. 1014-1020, June 1999.

[21] D. Timmerman, T. Bourne, A. Tailor, W. P. Collins, H. Verrelst, K. Vandenberghe, and I. Vergote, "A comparison of methods for preoperative discrimination between malignant and benign adnexal masses: the development of a new logistic regression model," American Journal of Obstetrics and Gynecology, vol. 181, no. 1, pp. 57-65, July 1999.

[22] L. Valentin, L. Ameye, A. Testa, F. Lcuru, J.-P. Bernard, D. Paladini, S. Van Huffel, and D. Timmerman, "Ultrasound characteristics of different types of adnexal malignancies Gynecologic Oncology," Gynecologic Oncology, vol. 102, no. 1, pp. 41-48, July 2006. 